\title{
Wicked but worth it: student perspectives on socio-hydrology
}

Morgan C. Levy ${ }^{\mathrm{a}^{*}}$, Margaret Garcia ${ }^{\mathrm{b}}$, Peter Blair ${ }^{\mathrm{c}}, \mathrm{Xi} \mathrm{Chen}^{\mathrm{d}}$, Sharlene L. Gomes ${ }^{\mathrm{e}}$, Drew B.

Gower $^{\mathrm{f}}$, Johanna Grames ${ }^{\mathrm{g}}$, Linda Kuil ${ }^{\mathrm{g}}$, Ye Liu ${ }^{\mathrm{h}}$, Landon Marston ${ }^{\mathrm{i}}$, Paul F. McCord ${ }^{\mathrm{j}}$,

Mahendran Roobavannan ${ }^{\mathrm{k}}$, Ruijie Zeng ${ }^{\mathrm{i}}$

a. Energy and Resources Group, University of California Berkeley, USA

b. Department of Civil and Environmental Engineering, Tufts University, USA

c. Department of Civil and Environmental Engineering, Imperial College London, UK

d. Center for Sustainability and Global Environment, University of Wisconsin-Madison, USA

e. Faculty of Technology, Policy, and Management, Delft University of Technology,

Netherlands

f. Department of Civil and Environmental Engineering, Princeton University, USA

g. Centre for Water Resource Systems, Vienna University of Technology, Austria

h. Department of Hydraulic Engineering, State Key Laboratory of Hydroscience and Engineering, Tsinghua University, China

i. Department of Civil and Environmental Engineering, University of Illinois at UrbanaChampaign, USA

j. Department of Geography, Indiana University, USA

k. School of Civil and Environmental Engineering, University of Technology Sydney, Australia

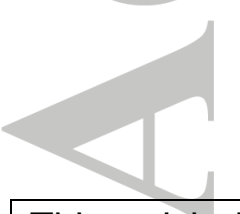

This article has been accepted for publication and undergone full peer review but has not been through the copyediting, typesetting, pagination and proofreading process which may lead to differences between this version and the Version of Record. Please cite this article as doi: 10.1002/hyp.10791 
* Correspondence to: Morgan C. Levy, Energy and Resources Group, University of

California Berkeley, USA. Email: mclevy@berkeley.edu

Issues concerning water security plague agricultural, residential, and industrial sectors worldwide, despite advances in the understanding of biophysical water system processes. Proposed solutions to water challenges have been inadequate because they do not account for the dual role of humans as both contributing to and subsequently adapting to problems. This reality has motivated researchers to consider human decision-making and activities as endogenous to water system dynamics (Thompson et al., 2013; Vogel et al., 2015). Sivapalan et al. (2012) introduced the concept of socio-hydrology as a "new science of people and water" to meet this challenge. Socio-hydrology aims to broaden the study of water cycle dynamics with explicit consideration of social processes, similar to the field of ecohydrology, which incorporates ecological processes into the study of water cycling. This poses difficulties. Unlike ecohydrology, which involves a synthesis of two natural science disciplines, socio-hydrology involves incorporation of social processes, which many consider fundamentally different from processes tackled traditionally by natural scientists and engineers.

Rittell and Webber (1973) define "wicked problems" as problems with unknown or indeterminate scope and scale, and for which there may be no definitive formulation or optimal solution - specifically problems of social policy and planning. It is possible to conceptualize socio-hydrology as a science that wrestles with wicked problems. Sociohydrology does not possess a precise set of principles or testable hypotheses characteristic of physical sciences, but advocates a holistic approach to examining water system challenges through inclusion of social processes (Lane, 2014; Troy et al., 2015; van der Zaag et al., 
2014). It is therefore challenging to unambiguously articulate socio-hydrology's guiding questions and methods, reconcile preferred and available data types, and define what modeling and prediction mean to this new field. However, far from being a deterrent, this wickedness is precisely what attracts and motivates the first generation of young researchers specializing in socio-hydrology - the doctoral student authors of this paper.

Student ambitions are practical: socio-hydrology is both necessary and inevitable. Researchers increasingly acknowledge the importance of incorporating social processes into the study of water resources (Montanari et al., 2015; Rajaram et al., 2015). In the original account of wicked problems, Churchman (1967) states that the decision to wrestle with the whole rather than part of a problem is fundamentally a moral decision. Students have witnessed the rise of sustainability research in the water, climate, and environmental sciences, along with the shortcomings of that research in connecting with human-decision-making, management and policy. Tackling the whole of the problem, despite its challenges, is the most appropriate way to acknowledge and address the needs of the communities we claim to serve.

This commentary distills $\mathrm{PhD}$ student perspectives on socio-hydrology, its challenges, and ways forward. Our discussion is informed by an anonymous 30-question survey designed by the two lead authors to evaluate perspectives and obtain insights on the practice of sociohydrology from a first generation of student socio-hydrologists. The PhD students who completed this survey had at least one year of experience conducting socio-hydrological research at the doctoral level (we invited $25 \mathrm{PhD}$ students to participate, and $16 \mathrm{PhD}$ students completed the survey - 13 co-authors and 3 acknowledged contributors). We identified students based on their participation in a series of socio-hydrology workshops hosted by the 
National Socio-Environmental Synthesis Center (SESYNC) in 2013-2015 and by recommendations from academic advisors to socio-hydrology students.

We first frame the conversation with a brief discussion of what socio-hydrology is and its application, including who socio-hydrologists are and approaches used. We do not explicitly address debates over the genesis and uniqueness of socio-hydrology (Sivakumar, 2012). Instead, we discuss how to improve synthesis across social and hydrological knowledge by examining three key challenges for pioneering practitioners: interdisciplinarity, data, and the ambiguities and demands of socio-hydrological prediction.

\section{What is socio-hydrology?}

Although variously defined in the literature, socio-hydrology can be summarized as the study of two-way interactions between humans and water systems resulting in the co-evolution of coupled human-water systems (see e.g. Carey et al., 2014; Gober and Wheater, 2014; Montanari et al., 2013; Pataki et al., 2011; Sivapalan et al., 2012). Co-authors of this paper generally agree on this definition, but have differences of opinion on its scope. For example, four out of 16 students see socio-hydrology as including processes that link scientific understanding to decision-making, while five out of 16 extend the scope to include consideration of changing social norms and values. Regardless, what distinguishes sociohydrological research from social scientific investigations of human interactions with water systems, or hydrological studies of human-regulated systems, is that socio-hydrology rigorously considers the dynamics of both system processes and their coupling. 
This bears significant overlap with other coupled-systems analyses, such as research using social-ecological systems (SES) or coupled human and natural systems (CHANS) frameworks (Liu et al., 2007; Ostrom, 2009). Still, socio-hydrology is distinguishable by its focus on the unique characteristics of water, and by its focus on quantifying feedbacks to improve hydrological prediction. Many coupled-systems analyses are descriptive, and where they are more than descriptive (see Schlüter et al., 2012), they often do not handle feedbacks as explicit dynamic processes, do not quantify the results of feedbacks, or they are tailored to a particular region or sector such as with some Integrated Water Resources Management (IWRM) models (see Bach et al., 2014).

\section{Socio-hydrology in practice}

Of the $16 \mathrm{PhD}$ students working in socio-hydrology who contributed to this commentary, nearly half come from an engineering background; a quarter are from interdisciplinary backgrounds with a social science focus; the remaining students are split across the geosciences, math and computer sciences, and physical sciences. Thus, we find that students practicing socio-hydrology come from diverse disciplinary backgrounds. In our survey, students had predominantly quantitative engineering or scientific training, however nearly half of all reported collaborations were with social scientists. This illustrates the important point that socio-hydrologists aspire to integrate theory, models, and data from both the hydrological and (quantitative and qualitative) social sciences. We are not hydrologists dabbling in the social sciences, or vice versa.

Socio-hydrological research consistently focuses on understanding the extent of human influence on one or more hydrological variables, and/or the impact of hydrological variables, 
in conjunction with moderating influences such as institutions, on human behavior. A few examples of research topics include: simulation modeling of water management feedbacks to surface and groundwater stocks and flows, analysis of river channelization and restoration with respect to changing social values, and study of farmer irrigation decision-making amidst water shortages. Socio-hydrologists are not only working to synthesize existing theory (akin to ecohydrology), but also work to synthesize across case studies.

There is no blueprint for conducting socio-hydrological research of this kind. Consequently, students use various approaches. A small subset of students have developed new frameworks specific to socio-hydrology (see e.g. Elshafei et al., 2014; Liu et al., 2014). Others explicitly ask methodological questions and seek new ways to study and model socio-hydrological systems (Garcia et al., 2015). Students are especially interested in incorporating social variables into models, rather than using them as system boundaries, as well as defining new state variables specific to socio-hydrological systems. Most students draw from existing disciplines and their vetted methods: physical hydrological models, micro- and macroeconomic theory, institutional analysis, network theory, agent-based modeling, geographic information systems and remote sensing, optimization, and applied statistics.

\section{Challenges and opportunities}

In exchange for being able to tackle exciting and timely problems, socio-hydrologists face unique challenges. First, increased effort, time, and funding are required to do or supervise research that spans multiple fields. Second, socio-hydrologists grapple with mixed biophysical and social data. Third, the complexity of coupled social and hydrological systems 
complicates a traditional understanding of prediction. We discuss these challenges in more detail below.

\section{Interdisciplinarity}

The opportunity to conduct interdisciplinary research motivated most students to pursue socio-hydrology, and all but one student contributor categorized her/his work as either crossor inter-disciplinary. Yet, students note that fostering collaboration across fields is not trivial. In order to do research that is truly socio-hydrological, tools from different disciplines cannot merely be stacked on top of one another. Instead, multiple perspectives must be applied in both framing and addressing a research question. For example, appending an economic analysis to the output of a hydrological model without incorporation of feedbacks would not be considered a socio-hydrological pursuit. However, modeling the interaction of economic and hydrological processes and drawing upon both fields to represent feedbacks, would (see Cai et al., 2003; Pande et al., 2014; Grames et al., 2015). The latter requires translating language between disciplines, resolving parameter units (e.g. time scales), and rethinking goals of estimation (e.g. optimal vs. realized production of a water-intensive good).

Given the need to master theory and methods across multiple disciplines, students are acutely aware that socio-hydrological research must be either a team effort, or one requiring more time than research in a single discipline. Additionally, there are barriers to teamwork across disciplines, especially across the social and physical sciences (Poteete et al., 2010). Students cited communication and collaboration difficulties as challenges. Scientists may be unfamiliar, and at times unduly critical, of theory and methods from outside their field that may enhance studies of coupled human and hydrological systems - especially with respect to 
the integration of qualitative social science approaches. Alternately, social scientists and planners may question the management and policy relevance of hydrological theory and science, limiting their engagement.

Data

Students use a variety of data types, including hydrological data (both in-situ and remotely sensed), stakeholder surveys, demographic statistics and economic data; synthetic data are used to investigate generalized, hypothetical cases for the development or testing of models. Whereas relatively long-term hydrological data may be available, corresponding social data may not be, or may only be available at different temporal or spatial resolutions (e.g. annual population statistics). Even in cases where both physical and social data are available, the methods and standards used to assess consistency and uncertainty for both types of data are different. Lastly, synthesizing across data to answer causal questions (i.e. the impact of management actions on hydrology and vice versa) remains difficult due to differences in data quality.

\section{Prediction}

The wicked complexity of socio-hydrology makes the path to prediction a challenging one to follow. Coupling social and hydrological systems amplifies uncertainties that already challenge prediction in both domains (see Milly et al., 2008; Viglione et al., 2014). Further, the state-space for these coupled systems, involving interdependent variables, processes, actors and institutions, cannot be pre-stated (Barabási, 2003; Ostrom, 2005). Thus, there is a split in student views regarding the potential for socio-hydrological prediction amidst complexity and uncertainty. Some students believe that given variability and uncertainty in 
socio-hydrological processes, the field should focus on the fundamental understanding of dynamics rather than making predictions or determining solutions to specific problems. Others hold the view that prediction is possible, but that socio-hydrology may need to spend a great deal of time on process-focused research before it can move on to prediction.

The methods and data used in socio-hydrology in part define the nature of and capacity for prediction (Blair and Buytaert, 2015). Just as the scale of data and level of process detail affects the scale and accuracy of prediction using hydrological models, the same is true for socio-hydrological modeling and prediction. For example, if aggregate data are used to model decision-making, the resulting model can only predict future decisions at the group, not individual, level. The inclusion of data and processes on different spatio-temporal scales presents difficulties when modeling with current techniques, and may restrict the resolution of modeling to the extent that predictions do not resemble output from a traditional hydrological model.

Customary solutions to prediction problems in hydrology, such as collection of additional data for improved model parameterization or use of ensemble predictions, may be difficult to apply in many socio-hydrological systems due either to lacking data or state-space uncertainty. Furthermore, a collection of well-developed models, which these kinds of efforts serve, does not yet exist.

\section{Looking Forward}

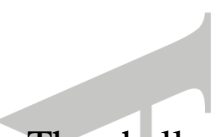

The challenges of socio-hydrology have inspired, not dampened, student enthusiasm. Student practitioners believe that socio-hydrology is uniquely qualified to re-define scales of human 
impact on water (Marston et al., 2015), investigate specific human-water feedbacks and their mechanisms, draw generalizable conclusions across cases, and ultimately provide better design of policy and management interventions. To work towards this potential, student socio-hydrologists provide the following insights.

\section{Addressing Interdisciplinary Overload}

Many students recommended working within teams to combat the challenges of interdisciplinary research. Enhancing communication and teamwork skills among early career researchers and advising faculty could decrease the challenges of interdisciplinary teamwork. Students also suggested having additional advisers and mentors outside their primary discipline. Faculty and university assistance in building networks of mentors invested in interdisciplinary research across departments can facilitate this. Conducting interdisciplinary research - not just in name - requires early and candid discussion between advising faculty about mentorship expectations, funding, publication goals and desired venues. Despite the challenges, nine out of 16 students find socio-hydrology's capacity to motivate researchers from different disciplines to work collaboratively to be a unique broader impact of the field.

As members of an interdisciplinary water sciences community, students believe it is important to improve understanding of relevant integrated analysis frameworks, such as CHANS, SES, and IWRM, and identify common ground. As socio-hydrology moves from process understanding to problem solving, it will be important to consider contributions from and to the development of decision-making tools, and connections to the study of science policy (Gober and Wheater, 2014). It is from areas of overlap (and awareness of areas of nonoverlap) that socio-hydrologists can learn the most. In the short term, we suggest exploration 
of which frameworks, models, and methods from different disciplines are most applicable to socio-hydrological systems analysis.

\section{Addressing Data Constraints}

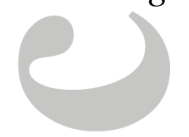

In light of perceived socio-hydrological data limitations, students collect new data and also find novel ways to use existing data. Socio-hydrology reframes water problems; with this reframing, new insights can emerge when reexamining existing data. Mapping out publically available, peer-reviewed social data, exploring the costs of obtaining proprietary data, or collaborating with data owners leverages existing resources. Where new data collection is required to inform model and theory development, researchers may consider incorporating experimental design into new pursuits following the approach pioneered by development economists (Duflo et al., 2007), and by focusing on data collection at multiple scales, such as household and utility-level water use.

While additional data collection efforts may address some gaps, others will remain. For example, the desire to understand significant or extreme transitions in a hydrological system or its management motivates several student research projects. The ability to test hypotheses about these transitions is limited not just by data availability, but by the rarity of the phenomena themselves. To address this, students recommended comparisons across case studies. This is key to the synthesis desired by socio-hydrologists. Methods and frameworks for case study comparisons are, however, limited. Therefore, devoting resources to facilitate comparisons of existing case studies would leverage existing work while developing new approaches for comparative study. 


\section{Addressing Predictive Capacity}

Addressing the prediction challenge of socio-hydrology is difficult in part due to different understandings of prediction, and aims of prediction. Following from Kumar (2011), water scientists in general face two types of prediction problems: first, problems related to the prediction of novel (unobserved) phenomena with the objective of understanding system dynamics and limits; and second, problems related to the prediction of future events in light of past observations with the objective of minimizing forecast error variance. Whether or not a researcher faces one or the other depends on his or her objective of either enhancing theory or making forecasts, the latter of which is generally case-specific. Researchers can address ambiguity in prediction goals by specifying which type of prediction problem they are addressing and adjusting performance expectations accordingly.

\section{Combining the complexity and uncertainty associated with social processes and data with} well-known uncertainties in hydrological prediction amplifies prediction challenges and highlights a defining characteristic of socio-hydrological systems: they are wicked. According to Conklin (2005), wickedness in a problem makes problem understanding central and solutions to those problems secondary. In other words, the problem-solving ambitions of socio-hydrology, which typically involve forecasting, may be secondary to improved understanding. Therefore, socio-hydrology may presently be better suited to the first type of prediction - understanding generalized system dynamics and limits within the restricted resolution of combined hydrological and social system units.

A focus on prediction in a probabilistic framework will be useful for socio-hydrology given heightened input uncertainty, as will be analyses that focus on uncertainty quantification in 
the use of combined hydrological and social data. A deeper appreciation for the limits of quantification and the contingent nature of the rules shaping social behavior will also be valuable. Several students voiced the opinion that modelers, in particular, must strike a balance between adequate process representation and parsimony (Hawkins, 2004; Ostrom, 2007). Grappling with the limits of predictability in socio-hydrological systems, students look to disciplines that have wrestled with the issue of uncertainty and prediction for complex systems (e.g. climate sciences, ecology, sociology, and economics).

\section{Conclusions}

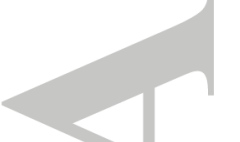

Understanding and predicting socio-hydrological systems may be a wicked problem, but the challenges of socio-hydrology are also its opportunities. The students who openly discussed the difficulties of pioneering work in socio-hydrology are the same students who see great potential for socio-hydrology's broader impacts. Half of the contributors maintain that sociohydrology will ultimately provide fundamentally different solutions to pressing environmental problems, and 14 out of 16 anticipate continuing to work in socio-hydrology in the future; the remaining two students expect to work on related issues.

Challenged by the lack of data or seemingly incompatible data sets, students look to other fields to broaden their knowledge of available data and to find new approaches to data collection and modeling. To cope with the challenge of interdisciplinarity, students look for areas of overlap with other integrative fields to eliminate the need to reinvent frameworks and methods, find mentors outside their primary field of study, and engage in team-based research efforts. Students question the engineering understanding of forecast-type prediction as the hallmark of success, and recommend patience in the push for applied socio-hydrology. 
Due to the wicked nature of socio-hydrological problems, we argue for an improved understanding of socio-hydrological system dynamics. Even though current work primarily focuses on enhancing a theoretical understanding, students remain inspired by sociohydrology's capacity to inform water management and policy in fundamentally new and more effective ways.

\section{Acknowledgements}

We acknowledge the valuable contributions of Yasmina Elshafei, Gopal Penny, and Ferdous Ruknul; thank Shafiqul Islam, Kent Portney, Murugesu Sivapalan, and Sally Thompson for their encouragement and feedback; and acknowledge The National Socio-Environmental Synthesis Center (SESYNC) for fostering student research on socio-hydrology. This paper represents a contribution of the Working Group on Socio-hydrologic Modelling and Synthesis to the Panta Rhei decadal initiative of the International Association of Hydrological

\section{Sciences.}

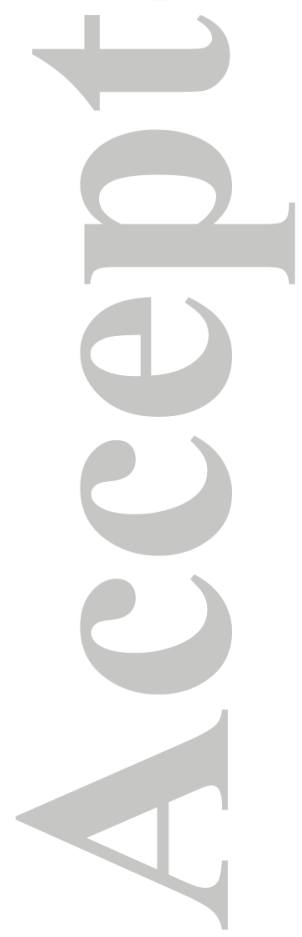




\section{References}

Bach PM, Rauch W, Mikkelsen PS, McCarthy DT, Deletic A. 2014. A Critical Review of Integrated Urban Water Modelling - Urban Drainage and beyond. Environmental Modelling \& Software 54 (April): 88-107. DOI: 10.1016/j.envsoft.2013.12.018

Barabási A. 2003. Linked: How Everything Is Connected to Everything Else and What It Means for Business, Science, and Everyday Life. Plume: New York, NY, USA.

Blair P, Buytaert W. 2015. Modelling Socio-Hydrological Systems: A Review of Concepts, Approaches and Applications. Hydrology and Earth System Sciences Discussions 12 (9): 8761-8851. DOI: 10.5194/hessd-12-8761-2015.

Cai X, Rosegrant MW, Ringler C. 2003. Physical and Economic Efficiency of Water Use in the River Basin: Implications for Efficient Water Management. Water Resources Research 39 (1): 1013. DOI: $10.1029 / 2001 \mathrm{WR} 000748$.

Carey M, Baraer M, Mark BG, French A, Bury J, Young KR, McKenzie JM. 2014. Toward Hydro-Social Modeling: Merging Human Variables and the Social Sciences with ClimateGlacier Runoff Models (Santa River, Peru). Journal of Hydrology, Creating Partnerships Between Hydrology and Social Science: A Priority for Progress, 518, Part A (October): 6070. DOI: 10.1016/j.jhydrol.2013.11.006.

Churchman CW. 1967. Wicked Problems. Management Science 14 (4): B - 141. DOI: 10.1287/mnsc.14.4.B141. 
Conklin J. 2005. Dialogue Mapping: Building Shared Understanding of Wicked Problems. John Wiley \& Sons, Inc: New York, NY, USA.

Duflo E, Glennerster R, Kremer M. 2007. Chapter 61: Using Randomization in Development

Economics Research: A Toolkit. In Handbook of Development Economics, edited by T. Paul

Schultz and John A. Strauss, 4:3895-3962. Elsevier. DOI: 10.1016/S1573-4471(07)04061-2

Elshafei Y, Sivapalan M, Tonts M, Hipsey MR. 2014. A Prototype Framework for Models of Socio-Hydrology: Identification of Key Feedback Loops and Parameterisation Approach. Hydrology and Earth System Sciences 18 (6): 2141-66. DOI: 10.5194/hess-18-2141-2014.

Garcia M, Portney K, Islam S. 2015. A Question Driven Socio-Hydrological Modeling

Process. Hydrology and Earth System Sciences Discussions 12 (8): 8289-8335. DOI: 10.5194/hessd-12-8289-2015.

Gober P, Wheater HS. 2014. Socio-Hydrology and the Science-policy Interface: A Case Study of the Saskatchewan River Basin. Hydrology and Earth System Sciences 18 (4): 141322. DOI: 10.5194/hess-18-1413-2014.

Grames J, Prskawetz A, Grass D, Blöschl G. 2015. Modelling the Interaction between Flooding Events and Economic Growth. Proceedings of the International Association of Hydrological Sciences 369 (June): 3-6. DOI: 10.5194/piahs-369-3-2015.

\footnotetext{
Hawkins DM. 2004. The Problem of Overfitting. Journal of Chemical Information and Computer Sciences 44 (1): 1-12. DOI: 10.1021/ci0342472.
} 
Kumar P. 2011. Typology of Hydrologic Predictability. Water Resources Research 47 (3):

W00H05. DOI: 10.1029/2010WR009769.

Lane SN. 2014. Acting, Predicting and Intervening in a Socio-Hydrological World.

Hydrology and Earth System Sciences 18 (3): 927-52. DOI: 10.5194/hess-18-927-2014.

Liu J, Dietz T, Carpenter SR, Alberti M, Folke C, Moran E, Pell AN, Deadman P, Kratz T,

Lubchenco J, Ostrom E, Ouyang Z, Provencher W, Redman CL, Schneider SH, Taylor WW. 2007. Complexity of Coupled Human and Natural Systems. Science 317 (5844): 1513-16.

DOI: $10.1126 /$ science.1144004.

Liu Y, Tian F, Hu H, Sivapalan M. 2014. Socio-Hydrologic Perspectives of the Co-Evolution of Humans and Water in the Tarim River Basin, Western China: The Taiji-Tire Model. Hydrology and Earth System Sciences 18 (4): 1289-1303. DOI:10.5194/hess-18-1289-2014.

Marston L, Konar M, Cai X, and Troy TJ. 2015. Virtual Groundwater Transfers from

Overexploited Aquifers in the United States. Proceedings of the National Academy of Sciences of the United States of America 112 (28): 8561-66. DOI: 10.1073/pnas.1500457112.

Milly PCD, Betancourt J, Falkenmark M, Hirsch RM, Kundzewicz ZW, Lettenmaier DP, and Stouffer RJ. 2008. Stationarity Is Dead: Whither Water Management? Science 319 (5863): 573-74. DOI: 10.1126/science.1151915. 
Montanari A, Young G, Savenije HHG, Hughes D, Wagener T, Ren LL, Koutsoyiannis D, Cudennec C, Toth E, Grimaldi S, Blöschl G, Sivapalan M, Beven K, Gupta H, Hipsey M,

Schaefli B, Arheimer B, Boegh E, Schymanski SJ, Baldassarre GD, Yu B, Hubert P, Huang Y, Schumann A, Post DA, Srinivasan V, Harman C, Thompson S, Rogger M, Viglione A, McMillan H, Characklis G, Pang Z, Belyaev V. 2013. 'Panta Rhei-Everything Flows':

Change in Hydrology and society-The IAHS Scientific Decade 2013-2022. Hydrological Sciences Journal 58 (6): 1256-75. DOI: 10.1080/02626667.2013.809088.

Montanari A, Bahr J, Blöschl G, Cai X, Mackay DS, Michalak AM, Rajaram H, Sander G. 2015. Fifty Years of Water Resources Research: Legacy and Perspectives for the Science of Hydrology. Water Resources Research 51 (9): 6797-6803. DOI: 10.1002/2015WR017998.

Ostrom E. 2005. Understanding Institutional Diversity. Princeton University Press:

Princeton, New Jersey.

Ostrom E. 2007. A Diagnostic Approach for Going Beyond Panaceas. Proceedings of the National Academy of Sciences 104 (39): 15181-15187. DOI: 10.1073/pnas.0702288104.

Ostrom E. 2009. A General Framework for Analyzing Sustainability of Social-Ecological Systems. Science 325 (5939): 419-22.

Pande S, Ertsen M, Sivapalan M. 2014. Endogenous Technological and Population Change under Increasing Water Scarcity. Hydrology and Earth System Sciences 18 (8): 3239-58. DOI: $10.5194 /$ hess-18-3239-2014. 
Pataki DE, Boone CG, Hogue TS, Jenerette GD, McFadden JP, Pincetl S. 2011. Socio-

Ecohydrology and the Urban Water Challenge. Ecohydrology 4 (2): 341-47. DOI:

10.1002/eco.209.

Poteete AR, Janssen M, Ostrom E. 2010. Working Together Collective Action, the Commons, and Multiple Methods in Practice. Princeton University Press: Princeton, New Jersey.

Rajaram H, Bahr JM, Blöschl G, Cai X, Mackay DS, Michalak AM, Montanari A, SanchezVilla X, Sander G. 2015. A Reflection on the First 50 Years of Water Resources Research. Water Resources Research 51 (10): 7829-37. DOI: 10.1002/2015WR018089.

Rittel HWJ, Webber MM. 1973. Dilemmas in a General Theory of Planning. Policy Sciences 4 (2): 155-69. DOI: 10.1007/BF01405730.

Schlüter M, Mcallister RRJ, Arlinghaus R, Bunnefeld N, Eisenack K, Hölker F, MilnerGulland EJ, Müller B, Nicholson E, Quaas M, Stöven M. 2012. New Horizons for Managing the Environment: A Review of Coupled Social-Ecological Systems Modeling. Natural Resource Modeling 25 (1): 219-72. DOI:10.1111/j.1939-7445.2011.00108.x.

Sivakumar B. 2012. Socio-Hydrology: Not a New Science, but a Recycled and Re-Worded Hydrosociology. Hydrological Processes 26 (24): 3788-90. DOI:10.1002/hyp.9511.

Sivapalan M, Savenije HHG, Blöschl G. 2012. Socio-Hydrology: A New Science of People and Water. Hydrological Processes 26 (8): 1270-76. DOI:10.1002/hyp.8426. 
Thompson SE, Sivapalan M, Harman CJ, Srinivasan V, Hipsey MR, Reed P, Montanari A, Blöschl G. 2013. Developing Predictive Insight into Changing Water Systems: Use-Inspired Hydrologic Science for the Anthropocene. Hydrology and Earth System Sciences 17 (12): 5013-39. DOI:10.5194/hess-17-5013-2013.

Troy TJ, Konar M, Srinivasan V, Thompson S. 2015. Moving Sociohydrology Forward: A Synthesis across Studies. Hydrology and Earth System Sciences Discussions 12 (3): 3319-48. DOI: $10.5194 /$ hessd-12-3319-2015.

Viglione A, Di Baldassarre G, Brandimarte L, Kuil L, Carr G, Salinas JL, Scolobig A, Blöschl G. 2014. Insights from Socio-Hydrology Modelling on Dealing with Flood Risk Roles of Collective Memory, Risk-Taking Attitude and Trust. Journal of Hydrology, Creating Partnerships Between Hydrology and Social Science: A Priority for Progress, 518, Part A (October): 71-82. DOI: 10.1016/j.jhydrol.2014.01.018.

Vogel RM, Lall U, Cai X, Rajagopalan B, Weiskel PK, Hooper RP, and Matalas NC. 2015. Hydrology: The Interdisciplinary Science of Water. Water Resources Research 51 (6): 440930. DOI: 10.1002/2015WR017049.

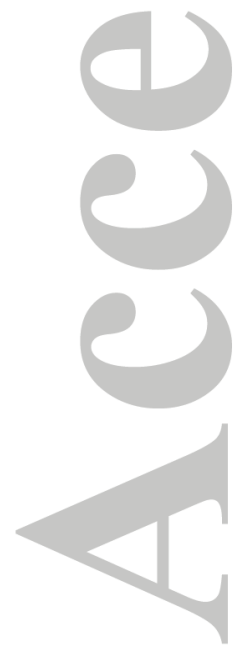

